Visualizing Objects, Places, and Spaces: A Digital Project Handbook

\title{
Playing with Historical Purpose and Agency
}

Jeffrey Lawler, Sean Smith

Published on: Jul 01, 2020

DOI: $10.21428 / 51$ bee781.b9b50a74

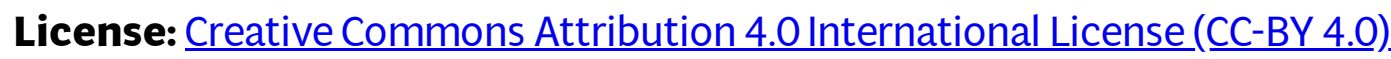




\section{Authors \& Project Roles}

\section{Authors:}

Sean Smith is a full time lecturer at CSU, Long Beach, and Co-Founder/Director of the CSULB Center for the History of Video Games and Critical Play.

Jeffrey Lawler is also a full time lecturer at CSU, Long Beach, and Co-Founder/Director of the CSULB Center for the History of Video Games and Critical Play.

\section{Roles:}

Sean Smith is co-creator of this curriculum and has taught this project in History 172 Early US History Survey in a large lecture section and in a small honors program section and has taught it in History 306 Playing the Past an upper-division history course at CSULB.

Jeffrey Lawler is co-creator of this curriculum and has taught this project in History 173 US History Survey Since 1865 in a large lecture section with student facilitators, in History 473 an upper-division California History course and has taught it in our games specific upper-division course History 306 Playing the Past at CSULB.

\section{Assignment URLs}

CSULB Center for the History of Video Games and Critical Play: https://www.criticalplay.org.

\section{Learning Objectives}

What did you want students to be able to do by completing this assignment?

1. Formulate a historical question, prepare research, and select appropriate primary and secondary sources.

2. Evaluate and analyze a variety of sources and craft a historical interpretation/argument.

3. Construct a historically plausible game in Twine or other game engine using traditional history research that conveys a clear and appropriate narrative. 


\section{Technology-Dependent Learning Outcomes}

Was there anything this assignment taught students that you felt they wouldn't have been able to learn through other types of class assignments?

The creation of a choice-based game subverts students' understanding of the historical process by engaging them directly in manufacturing possible historical choices that are based on real and reliable sources and historical events. This creative process provides students with a sense of agency and helps them create a narrative contingent on their own interpretations, an interpretation rooted in a solid historical methodology and traditional historical thinking skills, yet presented in a novel fashion. Moving the historical creation and narrative process over to students has the potential to reify students' connection to the past and its meaning, thus allowing students to engage with the past on their own terms while maintaining strong methodological underpinnings rooted in research, analysis, and contextual contingency.

Adding games discourse and integrating game engines such as Twine and other digital forms into class projects has provided a number of ways to help students think about and relate to the past. Specifically, we see Twine or game creation in general as a tool that provides students applicable historical methods of analysis, offers them agency in narrative creation, helps them develop an understanding of contingency and context, and reminds them that agency and choice are important elements when creating a representation of the past. Creating historically rooted games also helps students distinguish the difference between what happened in the past and how we tell accurate and meaningful stories that represent a fuller picture of the history of the United States.

In particular, having students engage in game creation teases out the difficulty and necessity of forming meaningful narratives about the past. As students research and formulate ideas about their games, the process of what evidence to use and connect becomes readily apparent. This process is markedly different than writing an essay and allows our students to struggle with the past and the varied ways historians tell stories. The affordances of digital projects used in our classrooms allow students to engage in a more diverse history and find their own meaning in multiple interpretations of the past. Most students also find a way to tell a story within their game that speaks to ideas and moments that are important to them. In fact, recent games include historical narratives about a variety of marginalized groups: The Black Panther Party, The Lavender Scare, Early 20th century immigration, or racial issues 
with Jazz during the 1920s in America. (To see examples of student work go to http://twinegames.criticalplay.net)

\section{Skill Level}

What is the course title and level?

This assignment has been successfully implemented in our freshman-level United States History Survey courses. It is also the core research project for our upperdivision history course History 306 Playing the Past: Games as Historical Narrative, Public Memory, and Cultural Representations. The iterations for each course differ in expectation and explanation depending on a variety of skill levels such as lower or upper-division, non-major or major, and honors or non-honor courses. Some of the lower division courses have integrated games as a pedagogical tool throughout the semester with the explicit idea that skills, research, content, and game creation will be integrated.

What kinds of prior knowledge is necessary to complete this assignment? How do students gain this knowledge?

For many of our students, their interest in history emerged from the games they played in their primary grade classrooms and the games that they currently play on their own game consoles and PCs. These games have had a deep impact on their historical understanding and have shaped their beliefs about history and historical study. In fact, an ongoing survey of the authors' undergraduate students (an informal classroom poll at the beginning of each semester of nearly 800 students from the fall semester of 2017 to the spring semester of 2019 in both upper-division and lowerdivision history courses) revealed nearly seventy percent of them became interested in history or the history degree program at our university because of a video game they had played or are currently playing.

While it is encouraging that video games bring students to history classes and help to foster an interest in studying the past, their influence remains problematic. This assignment hopes to adjust this prior knowledge and bring it more in line with academic understandings of the past. Students are already conditioned to read games uncritically by their past classroom experiences and the nostalgia they have for these games. Additionally, their consumption of contemporary history games with interpretations that serve the developers' agenda or narrative interests creates a prior historical knowledge that they bring to the classroom rooted in simplistic often heritage-based interpretations of the past. The games are written with notions of 
popular history and whether intended or not are loaded with historical myth or allusions that players internalize. Our students are clearly not equipped with the skills necessary to read video games critically and gauge their historical value. History is often conflated by students as a story well written and told. But the study of history is more than just the creation of a narrative of past events, it is a body of skills and knowledge that lead to historical thinking.

\section{Assignment Description}

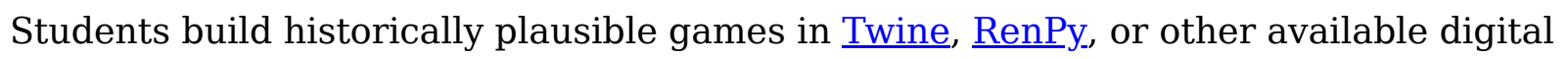
tools to help them think analytically and historically about the past. To accomplish this task they must complete several steps of historical research including collection, analysis, and synthesis of primary and secondary sources. Students organize these sources and their research into both storyboards and often we use timelines to set the historical context. The narrative structure of the games allows students to more clearly discern historical choice, agency, and the non-teleological nature of the past. The digital game creation process provides students with a non-traditional approach to the history class that challenges students to re-think cause and effect and the difficulty in creating meaning from the past. These games are collected and archived for play and comment on a class website.

\section{Time Needed}

How much time did you allot to this project?

This is a time intensive semester-long project and how to incorporate technology, historical concepts, and research skills depend on whether it was assigned in an upperdivision or lower-division class. After spending several semesters teaching this assignment in both semester-long and in a shorter time frame, we found digital game creation works best when 8 - 12 weeks are dedicated to the project. To succeed in the project students need time to do proper research and analysis, initial storyboards or passage cards, timelines, learning the technical aspects of their chosen game engine, writing the game, play testing, and final draft.

\section{Support \& Training}

What kinds of support or training did you provide to help students learn to use new techniques or specialized tools? 
Class time is spent teaching research methods including, the use of the internet and library for finding and evaluating primary and secondary sources, the application of Zotero for collection of their data, the formulation of historical questions, modeling narrative creation, instruction in some light coding in Twine and $\underline{\text { HTML}} \underline{\text { CSS }}$, all while making certain that the game is historically plausible. Importantly, we must be vigilant in the reinforcing of the idea that these are discipline-specific historical accounts in a playable form. They get both digital skills and traditional historical thinking skills.

\section{Resources}

Did you need any specialized equipment, tools, or human resources to make this assignment feasible? If so, please describe.

The game project is best suited in one of our University's Active Learning_Classrooms. These rooms facilitate group collaboration and provide access to a variety of technology that students and faculty can use to enhance and more actively engage and collaborate with during class time. We encourage students to bring their own devices and have seen students succeed using smartphones, tablets, and laptop computers. The rooms also allow for faculty to screen share in technological creation and programming processes in a group setting. It also allows for collaborative critiques and group gameplay, furthering their games and literacy and enhancing their more traditional historical research.

The library staff, and in particular the history librarian, provide a strong resource for our students regarding research and a variety of digital tools.

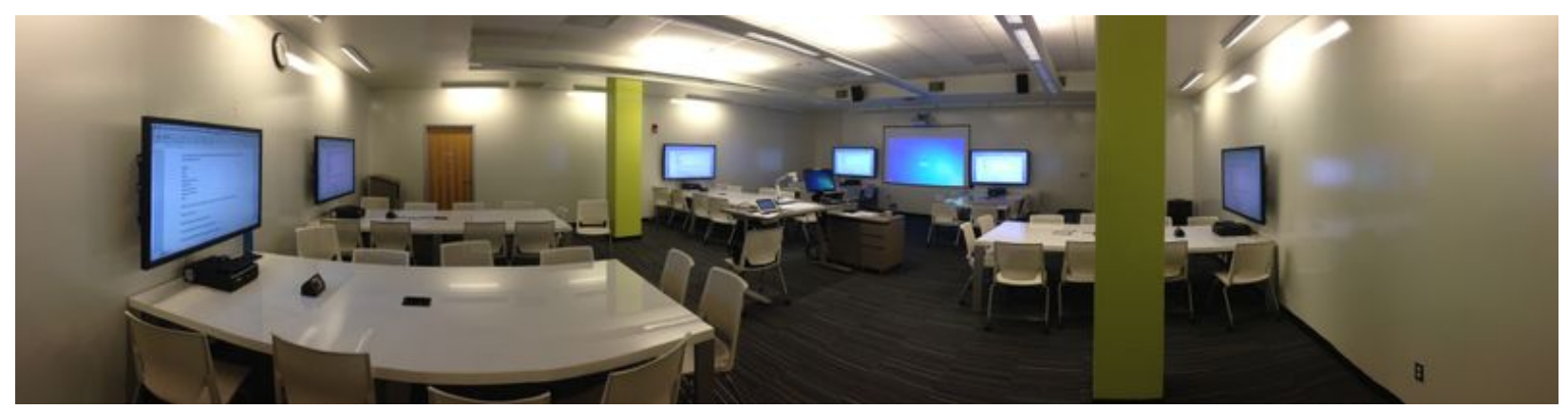

Active Learning Classroom, CSU, Long Beach. Photo: Authors

\section{Assessment}

How did you assess or grade this project?

Many components of the projects are assessed and graded for this assignment, including their historical research and bibliography (use of Zotero or other note- 
taking/research collection skills), historical questions and thesis, storyboards, game drafts, reflections and explanation of their use of integration of historical materials, and their final project. Students are provided with clear and appropriate guidelines for completion of each portion; they are also afforded the opportunity of providing feedback during game testing of all the games. Rubrics and peer reviews are used for the development and completion of the game.

\section{Challenges \& Opportunities}

If you assigned this project again, would you change anything? If so, what?

This assignment is constantly changing and being adapted to improve student comprehension and game creation. Each semester is different from the next with specific changes and adaptations being made based on students' games literacy and historical skills. We also struggle, especially in the lower division survey courses with questions of breadth and depth. This assignment offers students a deep dive into a specific subject often at the expense of breadth.

Describe any trouble spots or complications someone else might want to be aware of before trying a similar assignment in a course of their own.

The use of Twine and other game engines in the classroom has not proven to be a panacea, but when used in very particular circumstances and with sufficient engagement and feedback students do benefit. 